УДК 339.166

DOI: $10.21779 / 2500-1930-2018-33-2-32-38$

\title{
Т.Д. Аликеримова
}

\section{Перспективы развития традиционной и альтернативной энергетики в регионе}

Дагестанский государственный университет; Россия, 367001, 2. Махачкала, ул. М. Гаджиева, 43a; tamila@list.ru

Углеводородная энергетика существует около 150 лет. В силу ресурсных, экономических, экологических ограничений современная «индустриальная» энергетика постепенно должна быть заменена на «новую». Конечная цель - создание гибридной системы хозяйствования с иными механизмами производства и потребления энергии в регионе. Рассматриваются индикаторы развития мировой возобновляемой энергетики, ресурсы и потенциалы ВИЭ в Дагестане, программные мероприятия по увеличению доли ВИЭ в топливно-энергетическом балансе. Показано, что в Дагестане мало ископаемого топлива: ввозится до $100 \%$ твердого топлива и до $90 \%$ природного газа. Из возобновляемых источников энергии преимущественное применение находит гидро- и геотермальная энергия. В горных и предгорных районах начинает развиваться солнечная энергетика. Достаточно высоким энергетическим потенциалом обладает ветер, особенно в приморских районах. Учитывая растущую напряженность топливно-энергетического баланса республики и высокий технический потенциал использования ВИЭ на территории Дагестана, в качестве главного направления развития энергетики будущего предлагается кластер, нацеленный на обеспечение условий устойчивого развития региона и создания в нем центров активного использования экологически чистых возобновляемых источников энергии.

Ключевые слова: традиционная и альтернативная энергетика, возобновляемые источники энергии, микроГЭС, нормированная стоимость электроэнергии, геотермия, энергоресурcbl, топливно-энергетический комплекс.

Сегодня с абсолютной уверенностью можно утверждать, что будущее технологий лежит в плоскости пересечения дигитального (цифрового) и физического миров. Эта тенденция получает все большее распространение в таких отраслях, как энергетика, медицина, фармацевтика, легкая, пищевая и тяжелая промышленность. Нынешнее состояние тяготеет к так называемому «кризису истощения природных ресурсов», вынуждая административный аппарат и государственные корпорации интенсивно добывать то, что осталось. Исследования зарубежных и российских ученых показывают, что при текущих темпах потребления и объемах разведанных запасов ресурсов человеческому обществу хватит запасов нефти в промышленных целях на 50-80 лет, природного газа - на 60-80 лет. Ввиду того, что по данной проблеме существует очень много получивших политическую окраску дискуссий, поясним: нефть не будет исчерпана сразу - производных от углеводородов много и в каком-то виде они будут всегда. По истечении двадцати последующих лет состав нефти кардинально изменится. Добываемая в промышленных масштабах нефть с каждым годом становится все тяжелее. Цена ее переработки постоянно увеличивается по причине содержания в ней все большего объема смол, битумов и других примесей. При добыче нефти используется показатель EROEI коэффициент отношения энергии на выходе и на входе. В 1960-х гг. на каждую единицу энергии, вложенную в добычу, получали более ста единиц энергии нефти на выходе. В 90-х гг. XX века добываемая нефть обладала коэффициентом EROEI около тридцати, 
в 2000-м - только двадцать единиц, а в настоящее время EROEI колеблется между 1,5 и 1 для большинства вновь открытых месторождений.

С наступлением эры индустриализации и постиндустриализации, с расширением зоны техносферы, за счет Индии и Китая «кризис истощения природных ресурсов» стал ощутимее. Государства, обладающие теми или иными природными ресурсами, усиливают свое влияние, в то же время возрастает и давление на эти государства со стороны остальных.

В настоящее время население потребляет нефть, уголь и газ со скоростью в 1 млн раз превосходящую скорость их формирования в земной коре. В случае сопоставления сохранившихся в распоряжении общества полезных ископаемых и прогнозных алгоритмов развития мирового хозяйства, народоописания и внедрения инновационных технологий этот период составляет от нескольких десятилетий до ста лет. Оценив современную разведку, разработку месторождений и добычу энергоресурсов, можно заключить, что инвестиции и связанные с добычей риски для биосферы вышли на невиданный уровень.

Возобновляемые источники энергии (ВИЭ) - это один из видов энергии, прошедший с человеком все формации. До XVII века энергия солнца и энергия сжигания древесины, где путем фотосинтеза солнечная энергия и аккумулируется, были единственными источниками энергии для человеческого общества. Прогнозируя развитие энергетики, не будет лишним упомянуть, что Европа готова выбрать вектор развития, который основан на ВИЭ и на иной конфигурации энергосистем. Так, согласно последнему стратегическому плану Еврокомиссии «дорожной карте» по энергетике до 2050 г.) доля ВИЭ в конечном потреблении к 2050 г. определена на уровне 75 \%, а в электрогенерации $-97 \%[1]$.

Исследователями из Калифорнии и Стенфордского университета более пяти лет назад теоретически доказано, что солнечной энергии, энергии ветра, воды может быть достаточно для 100 \% перехода на ВИЭ. Условно необходимо около 4 млн ветровых турбин мощностью не менее 5 МВт каждая.

Обычно говорят о дороговизне ВИЭ. Однако сегодня стоимость альтернативной энергетики отличается дешевизной. Можно констатировать, что после 2011 г. она конкурирует по цене с традиционной.

Нельзя не сказать о таком показателе, как «нормированная стоимость электроэнергии» (Levelized Cost of Electricity - LCOE). LCOE - это цена электроэнергии, отпускаемой непосредственно с электростанции. В ближайшее время из-за снижения капитальных затрат и увеличения коэффициента использования генерирующих мощностей LCOE для солнечныX модулей будет продолжать снижаться. Все это в сочетании с отсутствием издержек на покупку топливных ресурсов, низкими операционными расходами и затратами на техническое обслуживание по прогнозам, приведет к тому, что к 2019 году показатель LCOE для солнечных батарей, будет ниже, чем средние розничные цены на электроэнергию.

Если рассматривать текущее состояние традиционных методов получения энергии в регионе, то нельзя не отметить, что в Дагестане получила реализацию программа комплексной модернизации Дагестанского филиала ПАО «РусГидро», которая предполагает повышение уровня надежности работы оборудования, эффективности использования водных ресурсов [3]. Данная программа предусматривает реконструкцию 8 гидротурбин, 2 гидрогенераторов, 7 гидротехнических сооружений, замену 13 гидротурбин, 13 гидрогенераторов, 11 трансформаторов и др. 
Программа ускоренного развития гидроэнергетики региона на период до 2020 года предусматривает освоение гидроэнергетических ресурсов в бассейне рек Сулак и Самур, реконструкцию и расширение действующих гидроэлектростанций. Имеется техническая возможность строительства пяти ГЭС на Андийском Койсу, трех ГЭС на Аварском Койсу и двух ГЭС на Каракойсу [2].

Стоит отметить роль и значение малой гидроэнергетики в регионе. Техникоэкономический потенциал малой гидроэнергетики в России превышает потенциал ветра, солнца и биомассы в сумме и составляет 60 млрд кВт·ч в год. Однако используется данный потенциал лишь на 1 \%. В регионе разработана технология поточного строительства малых ГЭС «Прометей» на основе специального оборудования, изготовленного по усредненным для горного рельефа стандартам. По технологии «Прометей» построены Агульская (600 кВт), Магинская (1,2 МВт) ГЭС, Амсарская (1 МВт), Аракульская (1,3 МВт) и Шиназская (1,3 МВт) малые ГЭС [6]. На стадии строительства и проектирования находятся 9 станций общей мощностью 62,4 МВт. Кроме того, в начале нулевых годов планировалась разработка проектов 10 малых ГЭС на разных реках республики и около 70 типовых малых ГЭС в бассейне реки Сулак мощностью по 0,6 МВт.

Республиканская целевая программа «Использование возобновляемых источников энергии в Республике Дагестан до 2020 года» была разработана в 2010-2011 гг. [3]. За последние годы многое изменилось и в Дагестане: объем валового регионального продукта, объем дотаций в республику из федерального бюджета. Возникла необходимость внесения изменений в программу с учетом новых реалий и с прогнозом расчетов до 2030 года. Нельзя оставить без внимания и поиск инвесторов, создание комфортных для них условий, чтобы обеспечить уверенность в безопасности инвестиций.

За 2012 г. добыто 193,8 тыс. т нефти с конденсатом и 326 млн куб. м природного газа, всего - 652 тыс. т у. т. Добываемая нефть почти полностью вывозится и не используется в формировании ТЭБ. Поэтому потребность в продуктах нефтепереработки почти полностью удовлетворяется за счет поставок из других регионов [6].

Что касается природного газа, то потребность республики в природном газе лишь на $10 \%$ удовлетворяется за счет собственной добычи.

Производство и потребление электроэнергии в республике из года в год растет и имеет положительное сальдо. В 2010 г. производство электроэнергии превысило суммарный объем потребления на 20 \%. В 2012 г. было выработано 3911,5 млн кВт•ч, а использовано 3613,2 млн кВт·ч. С учетом потерь электроэнергии $(608,4$ млн кВт・ч) из смежных энергосистем было получено 151,3 млн кВт·ч электроэнергии и передано за пределы 449,7 млн кВт•ч. В связи с ростом потребления электроэнергии в 2017 г. республика столкнулась с проблемой дефицита электроэнергии в размере более 2 млрд кВт·ч [8].

Согласно ГП РД "Энергосбережение и повышение энергетической эффективности в Республике Дагестан" спрос на электроэнергию к 2020 г. достигнет 9578 млн кВт·ч. Что касается рынка тепловой энергии, в настоящее время, по данным Федеральной службы государственной статистики, в этой сфере в республике заняты 27 предприятий, в эксплуатации находятся более 400 источников, относящихся к сектору централизованного теплоснабжения. В их числе Махачкалинская ТЭЦ с годовым отпуском тепла 321,7 тыс. Гкал, 412 котельных с годовым отпуском 1251,9 тыс. Гкал и 9 геотермальных термораспределительных станций с годовым отпуском 125 тыс. Гкал. В 2012 г. общая выработка тепла этими источниками составила 1698,6 тыс. Гкал. 
ГП РД "Энергосбережение и повышение энергетической эффективности в Республике Дагестан" к 2020 г. прогнозируется значительный рост производства тепловой энергии - до 3945 тыс. Гкал.

Уже сегодня ВИЭ могут обеспечить до $25 \%$ объема потребления топливноэнергетических ресурсов (31 млн т у. т/год), что создает благоприятные условия для решения энергетических и экологических проблем.

По запасам ВИЭ (без учета низкопотенциального тепла и биомассы) среди субъектов СКФО Дагестан занимает первое место (0,881 млн т у. т.). Далее идут Ставропольский край (0,603 млн т у. т.), Чеченская Республика (0,278 млн т у. т.), КарачаевоЧеркесская Республика (0,1 млн т у. т.), Кабардино-Балкария (0,087 млн т у. т.), Республика Северная Осетия - Алания $(0,045$ млн т у. т.) и Республика Ингушетия (0,016 млн т у. т.) [6].

В Дагестане в связи с истощением разведанных запасов нефти и газа сложились благоприятные условия для развития геотермальной энергетики на базе повторного использования скважин выработанных нефтяных и газовых месторождений. На этой основе в перспективе к 2030 г. можно осуществить ввод в эксплуатацию не менее $300 \mathrm{MBт} \mathrm{электрических} \mathrm{мощностей} \mathrm{и} \mathrm{выработать} \mathrm{более} 2$ млрд кВт·ч электроэнергии.

При современных ценах на топливо и энергию ГеоТЭС по удельным капиталовложениям будут сопоставимы с топливными электростанциями, а по себестоимости электроэнергии и экологической чистоте могут их превосходить. На разведанных месторождениях термальных вод возможно создание систем геотермального теплоснабжения с экономией природного газа до 500 млн куб. м/год. В дальнейшем при освоении технологии поддержания пластового давления для поровых коллекторов общая мощность геотермальных электростанций в Дагестане может достичь 1000 МВт с годовой выработкой 7 млрд кВт·ч электроэнергии.

Добыча сланцевого газа имеет преимущества в том случае, если осуществляется вблизи мест потребления и при этом инфраструктура и плотность населения в районах добычи позволяют проводить бурение большого числа скважин. Такой газ действительно получается очень дешевым [9]. Но стоит учитывать, что для сохранения уровня добычи надо постоянно бурить новые скважины; для транспортировки газа нужна отдельная трубопроводная сеть, так как сланцевый газ содержит много примесей и его нецелесообразно смешивать с природным газом; для экспорта сланцевого газа нужны мощности по его сжижению.

Из-за падения стоимости нефти и газа многие компании США находятся в весьма затруднительном состоянии и испытывают громадные финансовые проблемы. Например, акции компании архитектора американского сланцевого бума Гарольда Хэмма Continental Resources упали на 30 \% [10]. Но это не ведет к окончанию «сланцевой революции». Стоимость добычи сланцевого газа снижается для внутренних потребителей, стимулируя рост экономики. Ожидается создание более 500 тысяч постоянных и около 1,2 млн временных рабочих мест в сфере добычи и переработки сланцевого газа. Крупнейшая энергетическая корпорация США Exxon Mobil, выкупившая за 35 млрд долларов компанию ХТО Energy, добывающую сланцевый газ, тоже несет убытки. Однако компания имеет стратегию по разработке сланцевых пород на ближайшие 25-30 лет. Сланцевый газ постепенно завоевывает место на мировом рынке, добыча приводит к многочисленным проблемам, связанным с загрязнением воды, в связи с чем многие страны запретили применение гидроразрыва пластов, требующего крупных запасов воды, песка и химикатов. Вблизи месторождений скапливаются значительные объемы отработанной загрязненной воды, которая, как правило, не утилизируется с со- 
блюдением экологических норм. Грунтовые воды загрязняются толуолом, бензолом, диметилбензолом, этилбензолом, мышьяком и др. Экологический фактор способствовал наложению запрета на добычу сланцевого газа во Франции, в Германии, Чехии и Болгарии.

С 2008 года в России обсуждается тема использования имеющегося в ней газосланцевого потенциала [5]. Наша страна обладает огромными запасами сланцев, основная часть которых сосредоточена в пластах Баженовской свиты в Западной Сибири. Извлекаемые ресурсы оцениваются в 22 млрд баррелей нефти, что составляет почти половину ресурсов сланцевой нефти США. Вдоль западного склона Урала расположены два горизонта сланцев, частично выходящих на поверхность. В Якутии от Алдана до побережья Северного Ледовитого океана протянулся пласт сланцев, более удобный для разведки и добычи. Месторождения в Иркутской области и в Кузбассе (Барзасские сланцы) были открыты еще в тридцатые годы прошлого столетия.

В нашей стране добывать нефть на сланцевых месторождениях российские компании собираются в партнерстве с иностранными инвесторами. «Роснефть» планирует вести эту работу совместно с ExxonMobil. Американская нефтегазовая компания имеет соответствующий опыт и обладает необходимыми технологиями. В 2009 году ЕххonMobil сделала стратегическую ставку на нетрадиционную добычу энергоресурсов и вложила \$40 млрд. За эту сумму была куплена XTO Energy, занимающаяся производством газа из сланцев. Однако события 2014 года и санкции Запада исключили возможность использования технологий зарубежных фирм. Это, с одной стороны, резко сузило перспективы «сланцевой революции» в России, а с другой - вынуждает российские компании разрабатывать собственные технологии.

Необходима разработка масштабной Федеральной целевой программы «Горючие сланцы России», предусматривающей разведку сланцевых месторождений, разработку собственных технологий добычи сланцевой нефти и сланцевого газа, необходимые налоговые льготы. Российская Федерация должна быть готова переключиться на альтернативные источники энергии, когда начнут иссякать месторождения нефти и газа. Среди альтернативных наряду с ВИЭ и торфом надо рассматривать сланцевые нефть и газ.

В Дагестане в связи с истощением разведанных запасов нефти и газа сложились благоприятные условия для развития геотермальной энергетики на базе повторного использования скважин выработанных нефтяных и газовых месторождений. На этой основе в перспективе к 2030 г. можно осуществить ввод в эксплуатацию не менее 300 МВт электрических мощностей и выработать более 2 млрд кВт·ч электроэнергии.

При современных ценах на топливо и энергию ГеоТЭС по удельным капиталовложениям будут сопоставимы с топливными электростанциями, а по себестоимости электроэнергии и экологической чистоте могут их превосходить. На разведанных месторождениях термальных вод возможно создание систем геотермального теплоснабжения с экономией природного газа до 500 млн куб. м/год. В дальнейшем при освоении технологии поддержания пластового давления для поровых коллекторов общая мощность геотермальных электростанций в Дагестане может достичь 1000 МВт с годовой выработкой 7 млрд кВт·ч электроэнергии.

Основная цель предлагаемого кластера сосредотачивается на технологии и услугах в области возобновляемых источников энергии. Основными объектами, рассматриваемыми в кластере ВИЭ являются участники энергетического рынка: малые и средние компании, которые представляют сектор солнечной энергетики, сектор биомассы и другие сектора возобновляемых источников энергии. Средние и малые компании име- 
ют преимущество в виде коммерческой гибкости, но в то же время у них ограничены ресурсы, отсутствуют опыт, рынки сбыта, программы поддержки. При объединении этих компаний в энергетический кластер последние будут иметь возможность большего влияния на усиление конкуренции в получении доли рынка.

\section{Литература}

1. Дорожная карта сотрудничества России и ЕС в сфере энергетики до 2050 г. http://minenergo.gov.ru/node/1527.

2. Республиканская целевая программа «Энергосбережение и повышение энергетической эффективности в Республике Дагестан на 2011-2015 годы и на период до 2020 года».

3. Асаулов С.Г. Нетрадиционные источники углеводородов: сланцевый пузырь или сланцевая революция? // Российские нефтегазовые технологии. - 2014. - № 32 (9). C. 52-61.

4. Аскеров Н.С. Институционально-теоретические основы реализации стратегии развития кризисной территории // Региональная экономика: теория и практика. - М.: Финансы и кредит, 2013. - № 47 (326). - С. 19-24.

5. Аскеров Н.С. Горные территории Республики Дагестан: экономический потенциал и институты развития // Устойчивое развитие горных территорий. $-2016 .-$ Т. 8 , № 4. - С. 338-347.

6. Рабаданов М.Х., Гусейнов А.Г., Амиров Р.А., Аскеров Н.С., Ашурбеков Н.А., Бучаев Я.Г., Джаватов Д.К., Магомедбеков Г.У. Стратегический ресурс модернизации экономики Республики Дагестан: образование, инновации, кластеры: монография / под ред. М.Х. Рабаданова, А.Г. Гусейнова, Р.А. Амирова. - М., 2015.

7. Блохин А.И., Стельмах Г.П., Салихов Р.М., Петров М.С. Горючие сланцы - реальная альтернатива нефти // Вестник РАЕН. - 2014. - № 1. - С. 52-56.

8. Малинин Н.К., Рафаилова В.А., Шестопалова Т.А., Хазиахметов Р.М. Становление и развитие системы подготовки специалистов в области возобновляемых источников энергии в России. Альтернативная энергетика и экология (ISJAEE) (включен в перечень ВАК). - 2015. - № 10-11. - С. 18-26.

9. Ниналалов С.A. Возобновляемые эсточники энергии http://mkala.mk.ru/articles/2017/03/20/vozobnovlyaemye-istochniki-energii.html.

10. Попель О.С., Фрид С.Е., Коломиеи Ю.Г., Тарасенко А.Б. Климатические аспекты создания фотоэлектрических светосигнальных устройств на возобновляемых источниках энергии. Альтернативная энергетика и экология (ISJAEE). - 2015. - № 10-11). C. $98-106$.

11. Сэмюэль А. Ван-Вактор. Нефть благословенная и проклинаемая // Международный нефтегазовый бизнес от скважины до бензоколонки = Introduction to the global oil and gas business. - М.: Альпина Паблишер, 2014. - 240 c.

12. Цахаева К.Н., Бучаева С.А. Анализ эффективности государственной поддержки возобновляемых источников энергии (ВИЭ) // Управление экономическими системами: электронный научный журнал (включен в перечень ВАК) http://uecs.ru/marketing/item/3354-2015-02-11-13-44-08.

Поступила в редакцию 14 июня 2017 г. 
UDC 339.166

DOI: $10.21779 / 2500-1930-2018-33-2-32-38$

\section{Prospects for the development of traditional and alternative energy sector in the region}

\section{T.D. Alikerimova}

Dagestan State University; Russia, 367001, Makhachkala, M. Gadzhiev st., 43a; tamila@list.ru

The existing hydrocarbonic power has history, lasting for about 150 years. Owing to resource, economic and ecological restrictions the modern "industrial" power has to be gradually replaced with a "new" one. Its ultimate goal is to create a hybrid system of managing with other mechanisms of regional energy production and consumption. Throughout the process of analysis some parameters of the world renewable energy development are considered. Among them are the resources and potentials of renewable energy in Dagestan and program activities aimed at increasing the share of renewable energy in the fuel and energy balance. It is shown that there are scarce reserves of fossilized fuel in Dagestan: up to $100 \%$ of the solid fuel and up to $90 \%$ of natural gas are imported. From sustainable energy sources hydro- and geothermal power has predominant application. Solar power engineering began to develop in the upland regions. Wind has a sufficiently high power potential, especially in coastal areas. Taking into account the growing tension of the fuel and energy balance in the republic and a high technical potential of renewable energy utilization as the focus of future power engineering development in Dagestan it has been proposed to found a cluster, aimed at providing some conditions for sustainable development of the region and creating some centers where ecologically benevolent renewable energy is actively used.

Keywords: traditional and alternative power engineering, renewable energy sources, microhydroelectric power station, Levelized Cost of Electricity, geothermal energy, energy resources, fuel and energy complex.

Received 14 June, 2017 